\title{
GONIO-VESSELS IN NORMAL AND ABNORMAL EYES*
}

\author{
BY \\ SAKTIDAS CHATTERJEE \\ Manchester Royal Eye Hospital
}

SINCE the invention of the gonioscope in the early 20th century goniovessels have been noted and reported by several authors, but no detailed analysis of them is available. Duke-Elder and Goldsmith (1951) described "fine vessels coursing underneath the surface of the ciliary band" in blueeyed persons; and Sugar (1943) noted, again in blue eyes, delicate blood vessels among iris processes. These vesṡels are commonly noticed during routine gonioscopic examination in patients in our glaucoma clinic.

An attempt is made in the present paper to classify gonio-vessels and assess their incidence in both normal and abnormal eyes.

\section{Present Investigation}

For the purpose of this study 100 normal and 111 abnormal eyes were examined gonioscopically in detail. Special attention was paid to the nature and distribution of these vessels and also to the presence or absence of any abnormality at the angle. Goldmann's flangeless gonioscopy lens was used in conjunction with the Haag-Streit slit lamp, the high magnification being preferred. Difficulty was experienced in examining the angle at the sides even with the use of the deflecting prism.

All 211 eyes had medium or wide angles.

The 111 abnormal eyes may be classified as follows:

(i) Fifty had iridocyclitis; acute cases were not included as the hazy media made detailed examination impossible.

(ii) 25 had open-angle glaucoma.

(iii) 25 had senile cataracts.

(iv) Four had thrombotic glaucoma.

(v) Four had diabetic retinopathy.

(vi) Two had iris root tumours.

(vii) One had an obstruction of a peripheral branch of the central retinal vein.

* Received for publication May 5, 1959. 
Of the total of 211 eyes, 26 had a brown iris and the remaining 185 (88 per cent.) had a blue iris; all the patients were fair-skinned.

\section{Results}

\section{(A) Gonio-vessels in Normal Eyes}

Four types of vessels were found (Figure). The incidence of each type is shown in the Table (opposite).

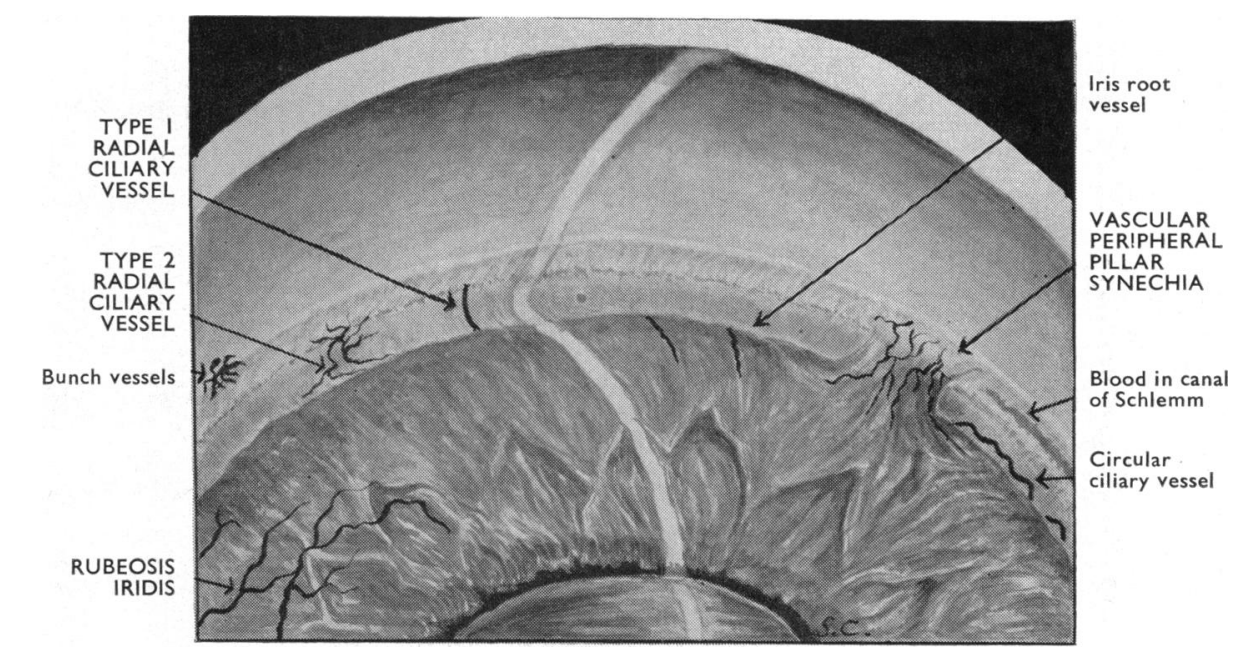

FIGURE.-Diagram showing various types of normal and abnormal gonio-vessels.

(1) Circular Ciliary Vessel.-This is the commonest type (65 per cent., i.e. 65 of 100 normal eyes). It appears to be a single wavy trunk, bright pink in colour, running in the ciliary band of the angle; it is thus circular in its course, concentric with the pupil. It is strictly limited by the borders of the ciliary band, but disappears at places into the ciliary body, and may therefore be visible in one or several positions. Branches were seen in two eyes only; they came off at right angles to the main trunk and disappeared either into the iris or into the sclero-corneal trabeculae (trabecular band).

(2) Radial Iris Root Vessels.-These were seen only in blue eyes. They appeared as thin, red, solitary streaks radiating towards the pupil from the ciliary end of the iris root. They were short, soon disappearing into the iris stroma. They always had a whitish border on each side. Sometimes such a vessel was found jutting into the ciliary band, but a careful observation always revealed a hump of the root of the iris in which it was placed. The greatest number seen in one eye was ten. These vessels were found in only twelve out of 100 normal eyes. They differed from the vessels seen in 
TABLE

INCIDENCE OF GONIO-VESSELS

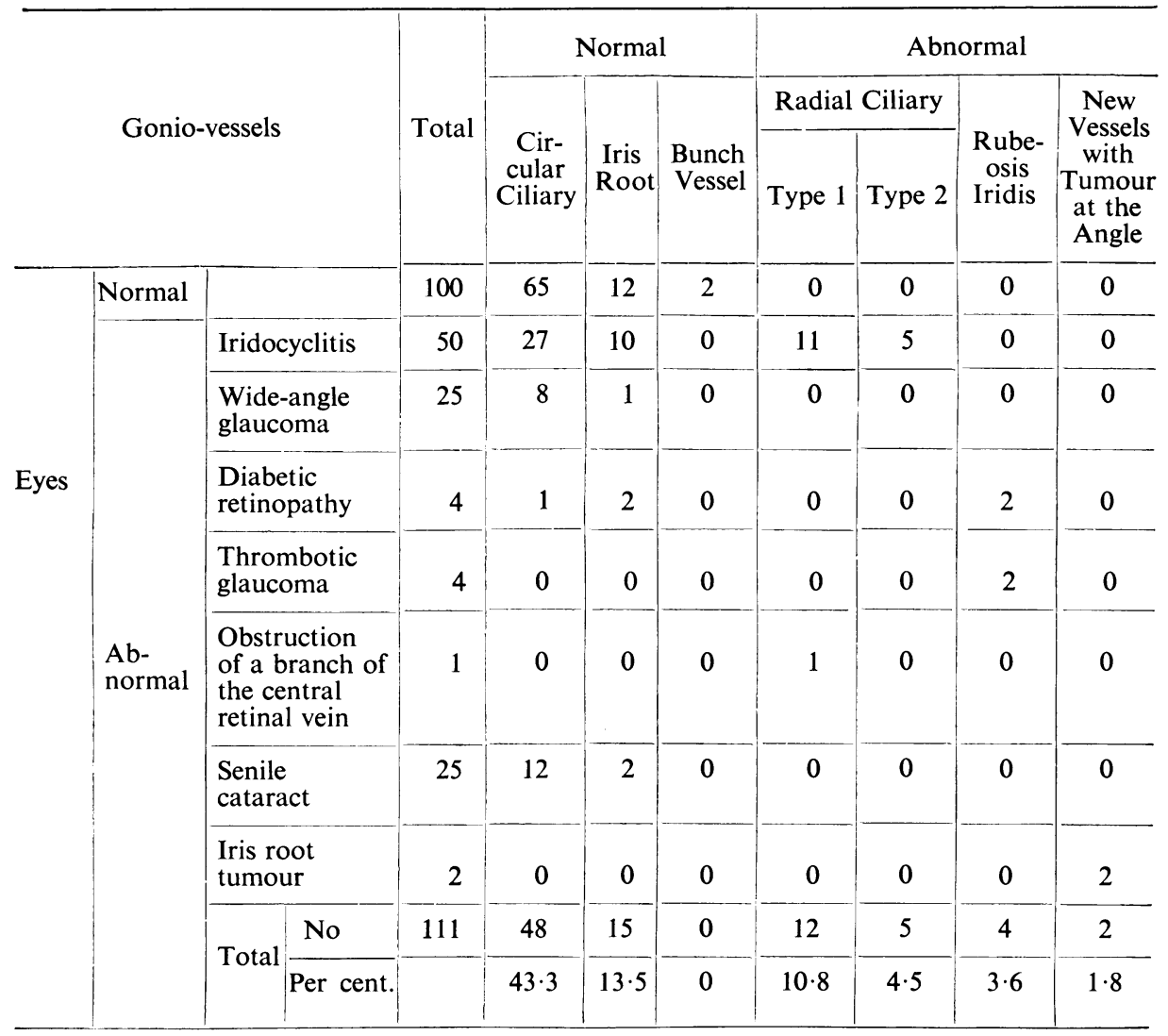

rubeosis irides in that they were not branched or irregular but strictly radial and did not appear to be new vessels.

(3) Blood in the Canal of Schlemm.-This appeared as a flat red band of variable width running along the trabecular band. It did not extend on to the ciliary band. In some cases it could be traced all around but usually appeared in segments. It was not always seen immediately after applying the gonioscopy lens, but blood tended to appear in the canal on prolonged manipulation with the instrument. The number of eyes showing this phenomenon was not recorded.

(4) Bunch Vessels.-In two cases a peculiar bunch of tiny vessels was noted near the sclero-corneal trabeculae. In one case this was placed at the anterior boder of the trabeculae and in the other it showed extension into the trabecula towards the canal of Schlemm. 


\section{(B) Gonio-Vessels in Abnormal Eyes}

Except for bunch vessels all the normal types of vessels were also seen in abnormal eyes. In addition other types of vessels were noted which were not seen in normal eyes. These are shown in the Figure. Their incidence is shown in the Table.

(1) Radial Ciliary Vessels.-These were found mostly in iridocyclitis, being present in only one case without iritis. They appeared as tiny red vessels running radially across the surface of the ciliary band, ending sharply at the iris root so that they could not be traced into the iris. Anteriorly they ended at variable levels in the ciliary band area or in the trabecular band area.

Two types of such vessels were noted; the first was characterized by being solitary and strictly radial, and the second was generally radial but with irregular branching and anastomosis. Neither type extended beyond the limits above mentioned.

Eleven out of fifty eyes with iridocyclitis showed Type 1 vessels and five showed Type 2 vessels. The one eye without iritis in which a Type 1 vessel was seen showed an occlusion of a peripheral branch of the retinal vein, the remainder of the eye being normal.

(2) Rubeosis Iridis.-In this condition delicate new vessels are formed on the surface of the iris. They are irregularly distributed with branches and anastomoses. When they extend on to the iris root they are seen by the gonioscope as new vessels on the iris root.

Two of the four eyes with thrombotic glaucoma and two of the four eyes with diabetic retinopathy showed rubeosis iridis extending to the root of the iris, but in none did the vessels extend further into the angle.

(3) Vascular Synechiae and Tumours at the Angle.-Although peripheral anterior synechiae were seen in many cases of old iridocyclitis, only a few were vascularized. These synechiae were obvious strands of iris root adhesions to the trabecular band or neighbouring cornea. New vessels in them appeared to arise from the iris root and to branch over the adhesion areas of the two structures.

Such peripheral vascular synechiae may be rather extensive in areas of thrombotic glaucoma. Two of four cases of thrombotic glaucoma showed these wide adhesions apart from the rubeosis iridis.

The two eyes with an iris root tumour showed a large wavy vessel at the angle, one end connected to the tumour while the other disappeared beyond the root of the iris. 


\section{Discussion}

Histological examination of the meshwork at the angle of the anterior chamber did not show any blood vessel (Ashton, Brini, and Smith, 1956; Flocks, 1956). Therefore the circular ciliary vessel that is seen in normal eyes must lie in the ciliary body, but it is placed so superficially as to be seen through the transparent meshwork. Obviously it will be seen better in non-pigmented than in pigmented eyes, although in the present series the circular ciliary vessel was noted in four out of 26 brown eyes.

Radial iris root vessels appear to be superficially placed normal iris vessels and are more often seen when dilated as in cases of iritis (Gorin and Posner, 1957).

Bunch vessels are relatively rare. They appear to consist of a collection of small vessels possibly associated with the canal of Schlemm.

The mechanism of thrombotic glaucoma from the production of vascular peripheral synechiae has been beautifully described by Redmond Smith (1955), according to whom a network of new vessels appears in the angle and is followed by extensive peripheral synechiae. This appears to be a different condition, not connected with the rubeosis iridis. The latter condition can however extend into the angle in some cases of diabetes (Duke-Elder, 1940), where it shows obvious connections with the rubeosis itself.

Radial ciliary Type 2 vessels are thin and look like new vessels, and are only seen in iridocyclitis. They are different from the above in that they are not associated with any synechia, obstruction of retinal vein or rubeosis iridis.

Radial ciliary Type 1 vessels, on the other hand, do not look like new vessels as they are too stout and too straight. This condition is seen more often in eyes with active or old iridocyclitis but not associated with peripheral synechiae. From the description of four cases of bilateral heterochromic cyclitis given by François and Beheyt (1955), it appears that these authors observed similar types of vessels which were described as tiny radial horizontal vessels at the angle. Franceschetti (1955) also noted tiny vessels at the angle in five out of sixteen cases of heterochromic cyclitis.

The significance of either type of radial ciliary vessel is however uncertain.

The vascular peripheral synechia formed in iridocyclitis is well known (Sugar, 1943; Ferguson, 1956) and needs no explanation.

Troncoso (1947) noted new vessels at the anterior angle chamber which were feeding an iris root tumour. These do not however help in detecting the origin of the tumour as the origin of the vessels themselves is not obvious. 


\section{Summary}

100 normal and 111 abnormal eyes were examined gonioscopically to study the nature and distribution of gonio-vessels. These vessels have been classified as follows:

(A) Normal gonio-vessels

(i) Circular ciliary vessel

(ii) Iris root vessel

(iii) Blood in the canal of Schlemm

(iv) Bunch vessel

(B) Abnormal gonio-vessels

(i) Radial ciliary vessels

(a) Type 1, solitary

(b) Type 2, branching anastomosing

(ii) Rubeosis iridis

(iii) Vascular synechiae and tumours at the angle.

The literature on this subject and the nature of these vessels are discussed. The significance of the radial ciliary vessels is not known.

I wish to thank Mr. P. L. Blaxter and Dr. A. Stanworth for their help and encouragement in writing this paper. I am also grateful to Miss E. Brown for secretarial help.

\section{REFERENCES}

Ashton, N., Brini, A., and SMith, R. (1956). Brit. J. Ophthal., 40, 257.

DUKE-ELDER, S. (1940). "Text-book of Ophthalmology", vol. 3, p. 2385, Kimpton, London. and GolDSMITH, A. J. B. (1951). "Recent Advances in Ophthalmology", 4th ed., p. 78. Churchill, London.

FERGUSON, W. J. W. (1956). Trans. ophthal. Soc. U.K., 76, 659.

Flocks, M. (1956). Arch. Ophthal. (Chicago), 56, 708.

FrANCESCHETTI, A. (1955). Amer. J. Ophthal., 39, No. 4, Part II, 50.

FrançoIs, J., and BeHEYT, J. (1955). Ann. Oculist. (Paris), 188, 55.

GORIN G., and PosNER, A. (1957). "Slit-Lamp Gonioscopy", pp. 102, 105 . Williams and Wilkins, Baltimore.

SMIth, ReDMOND, (1955). XVII Conc. Ophthal. 1954, Canada, U.S.A. Acta, vol. 2, p. 1164.

SUGAR, H. S. (1943). In "Biomicroscopy of the Eye", ed. M. L. Berliner, vol. 1, p. 598. Hoeber, New York.

Troncoso, M. U. (1947). “A Treatise on Gonioscopy”, p. 144. F. A. Davis, Philadelphia. 